\title{
Congenital Symmastia: A Four-Step, Minimally Invasive Approach
}

\author{
Neha Jain ${ }^{1}$ Uthraa Thambiran ${ }^{1}$ Leena Jain ${ }^{1}$ Siddharth Prakash ${ }^{1}$ Shrirang Purohit ${ }^{1}$ Samir Kumta ${ }^{1}$ \\ ${ }^{1}$ Department of Plastic and Reconstructive Surgery, Lilavati Hospital \\ and Research Center, Bandra Reclamation, Mumbai, Maharashtra, \\ India \\ Address for correspondence Neha Jain, DNB Plastic Surgery, \\ Department of Plastic and Reconstructive Surgery, Lilavati \\ Hospital and Research Center, Bandra Reclamation, Mumbai, \\ Maharashtra 400050, India (e-mail: drnehajain3086@gmail.com).
}

Indian J Plast Surg 2020;53:140-143

\author{
Abstract \\ Keywords \\ - congenital symmastia \\ - liposuction \\ - transdermal bolster \\ sutures
}

Symmastia is a rare condition in which breasts are unified medially due to aberrant development of mammary tissue in the intermammary region, resulting in the appearance of an intermammary web. There are limited reports on this rare anomaly and hence, no standard protocols on its management. Additionally, creating a normal cleavage in these young patients without scars over or around the breast is a challenge from an esthetic standpoint. In this article, we present a case of congenital symmastia corrected by four steps: liposuction of the intermammary region, use of suction drains along medial breast border, transdermal bolster sutures, and customized compression garment. Esthetic creation of the medial breast footprint and good preservation of breast contours was achieved with considerably less scars. Thus, we propose our four-step approach as an effective, minimally invasive method for treating congenital symmastia.

\section{Introduction}

Symmastia is a rare condition characterized by unified appearance of both the breasts due to aberrant development of mammary tissue in the intermammary region, described as the intermammary web. The principles of its surgical correction are emptying of the intermammary space and redraping of the presternal skin over the chest wall in midline, thus recreating the breast footprint medially. Here, we present a simple, minimally invasive, four-step approach for management of congenital symmastia.

1. Liposuction in presternal region.

2. Suction drain placement along medial border of breasts.

3. Two pairs of transdermal bolster sutures.

4. Customized pressure garment.

\section{Case Report}

A 23-year-old unmarried female presented in our clinic with complaints of absence of cleavage noticed since puberty. She had undergone liposuction 2 years ago for addressing the abnormality. No pressure garment was used then. She also underwent a fibroadenoma excision in the left breast 4 years ago. Breast development appeared normal corresponding with age with adequate volume, mild breast asymmetry and no ptosis. She had classical signs of symmastia such as absence of cleavage, united breasts, and intermammary web (-Fig. 1). Scars of previous procedures were seen. A thin groove was palpated in the intermammary region probably as a result of the liposuction done earlier.

A customized, inverted T-shaped pressure garment was made before surgery. Preoperatively, breast footprint and inframammary crease were marked in sitting position. A $2-\mathrm{cm}$ wide rectangle was marked extending from sternal angle above till the inframammary crease and curving outwards inferiorly, recreating the medial breast footprint. This corresponded to the area of liposuction ( - Fig. 2).

Under general anesthesia, intermammary region was infiltrated and aggressive liposuction was done with a 3-mm cannula in the marked areas through ports placed at the medial end of inframammary crease. Gradual fanning was done on either sides, into the medial breast region to obtain a subtle slope of breast projection. Suction drains were passed through the port incisions and placed along the medial borders of the breasts.
DOI https://doi.org/ 10.1055/s-0040-1710087 ISSN 0970-0358.
License terms

(ㅇ) (1) $\Theta \circledast$ 


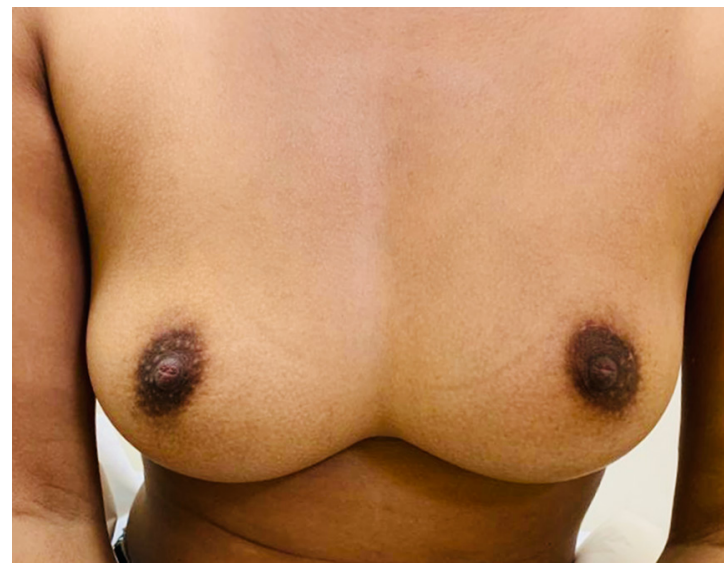

Fig. 1 Preoperative frontal view of 22-year-old female presenting with congenital symmastia. Note the classical signs: absence of cleavage and unified breast appearance.

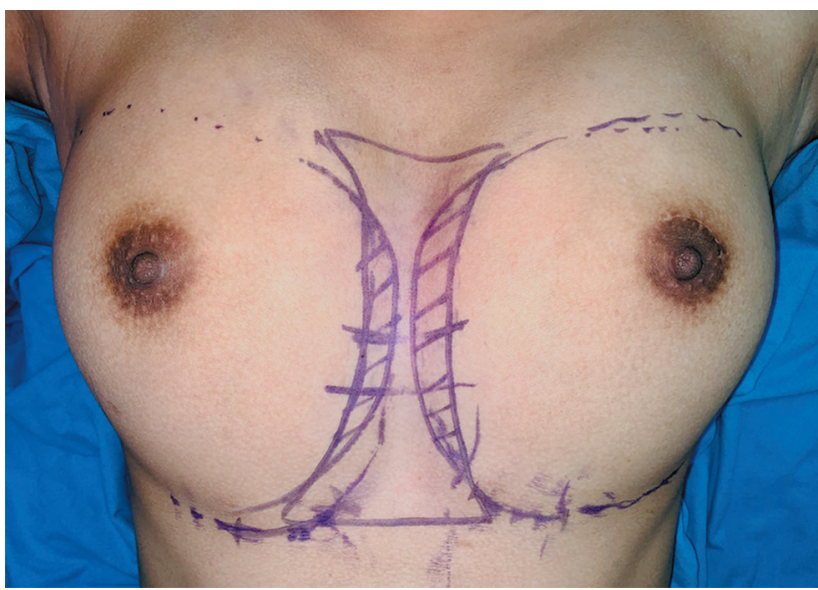

Fig. 2 Preoperative Markings. Breast footprint and inframammary crease marked. Area of liposuction marked as a $2-\mathrm{cm}$ wide rectangle in inter-mammary region from sternal angle above till the inframammary crease and curving outwards inferiorly.

With suction applied, the skin flaps were seen apposing well with the bed simulating a cleavage. Two pairs of transcutaneous bolster sutures were applied at the level of nipple areola complex (NAC) and $2 \mathrm{~cm}$ below it, to reinforce this apposition of skin to the underlying periosteum. Sutures were taken with 4-0 polypropylene and tied over foam pieces to prevent pressure necrosis ( - Fig. 3). Pressure garment was applied immediately postsurgery and continued for 3 months ( - Fig. 4). Drains were removed 2 weeks postoperatively and bolster sutures at 3 weeks. Patient was advised to massage all scars with scar remodeling gels. In the early postoperative period, mild dimpling of the skin was noted at the site of bolster sutures which settled with time. Nine months postoperatively, good result has been maintained with skin flaps well adherent to the bed in the intermammary region, normal breast contours, and mature flat supple scars which have faded substantially ( - Figs. 5 and 6 ).

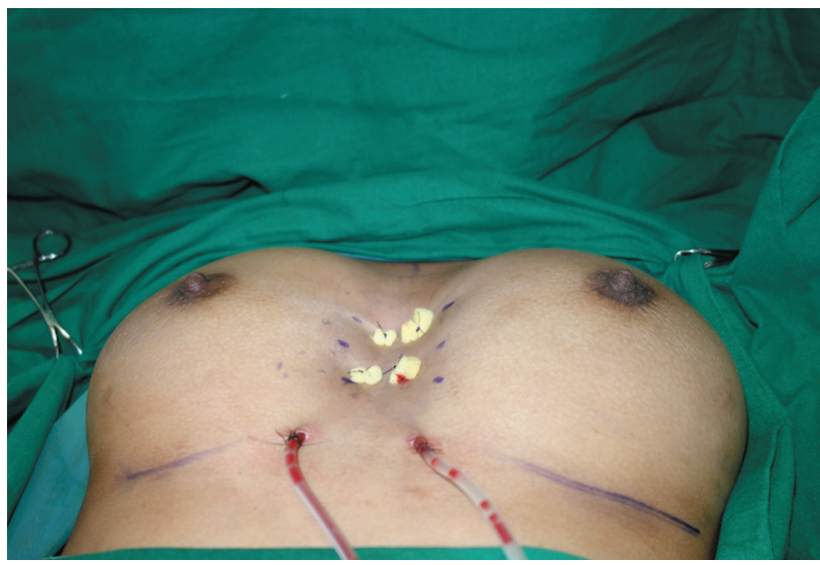

Fig. 3 Intraoperative picture showing immediate post liposuction result with suction drains and Transdermal bolster sutures in situ tied over pieces of foam.

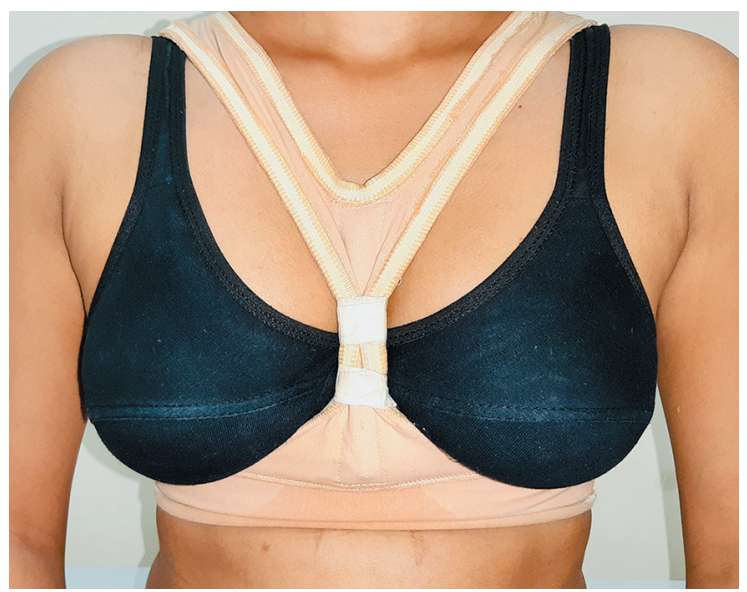

Fig. 4 Inverted T-shaped customized pressure garment.

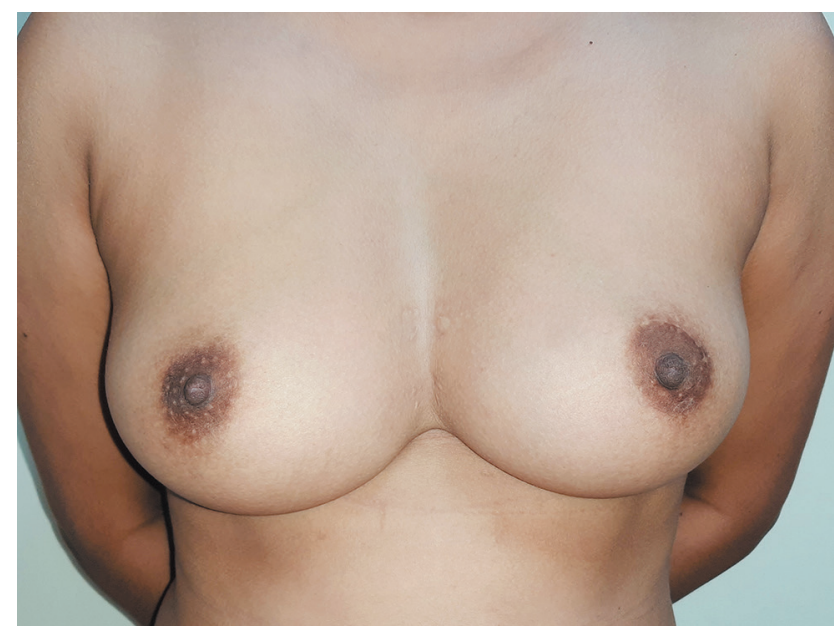

Fig. 5 Postoperative frontal view at 9 months. 


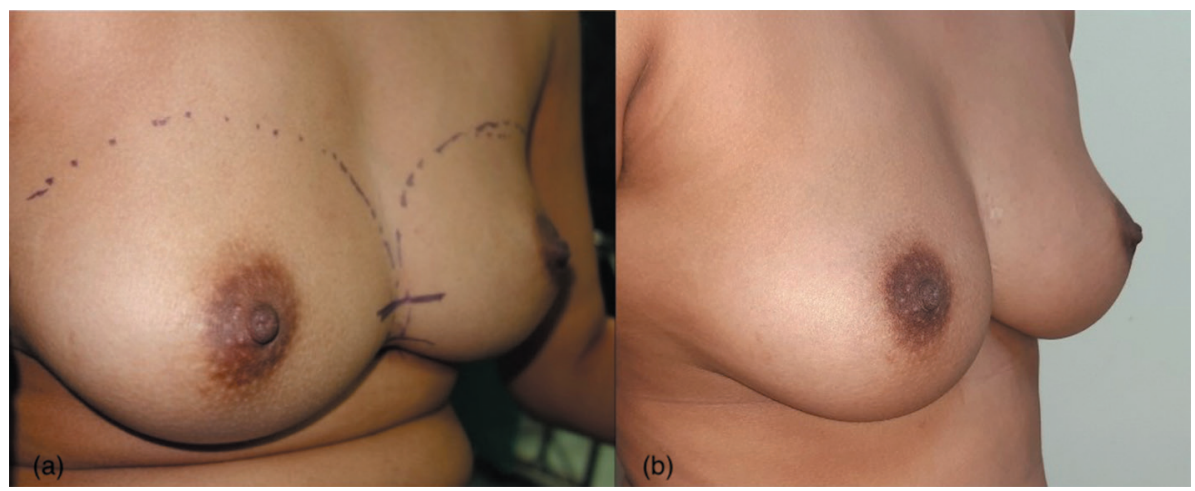

Fig. 6 (a) Preoperative and (b) Postoperative three-quarter view at 9 months.

\section{Discussion}

Congenital symmastia patients present at a rather early age for correction as the unified appearance of breasts is esthetically displeasing and unacceptable. Early reports of surgical management by Spence consisted of rotating triangular skin and soft tissue flaps, of intermammary web, superiorly and suturing to medial pectoral fascia, ${ }^{1}$ while McKissock proposed excision of the excess intermammary skin. ${ }^{2}$ Later, Salgado and Mardini demonstrated the use of suction-assisted lipectomy of the inter mammary fatty tissue and subdermal fixation sutures in the midline using a periareolar approach, redraping the excess skin. ${ }^{3}$ This, however, can cause conspicuous scars, hence Piza-Katzer et al utilized a submammary incision for the same. ${ }^{4}$ With better understanding of breast anatomy and Blondeel's three-step analysis, namely, footprint, conus, and skin envelope, Sillisen delineated the anatomical differences in symmastia. ${ }^{5}$ In symmastia, the medial footprint (adherence of the skin with underlying periosteum) of both the breasts is lost resulting in an eight-shaped footprint of both breasts together. Further, he proposed use of liposuction and recreation of the medial footprint with subdermal fixation sutures. In patients with associated macromastia, reduction mammoplasty was recommended. ${ }^{5}$ Recently, Sadaka and Allam advocated a similar three-step approach through inframammary incision with customized compression. ${ }^{6}$ On the contrary, Poteet et al proposed an aggressive approach stressing on excision of preternal soft tissue by direct approach and use of biological mesh to prevent medial migration accompanied with quilting sutures and compression. ${ }^{7}$ All the above mentioned approaches involved inframammary incisions for either soft tissue excision or presternal fixation. Most studies also discourage use of transdermal sutures to avoid hypertrophic scarring in the presternal region. ${ }^{5,8}$

Young, unmarried patients with normal sized breasts would be concerned about incisions over or around the breast. Future concerns of breastfeeding and nipple sensation makes procedures like reduction mammoplasty unviable for younger patients without macromastia.
Liposuction has the merits of minimal incisions and uniform removal of presternal soft tissue excess., ${ }^{5,6,8} \mathrm{We}$ focused on removing a thin crescent of breast tissue along the medial border of the breast to obtain subtle curve of breast projection. But, liposuction alone may not give the desired result to maintain the separation between the breasts. Passage of suction drains through the same opening was done as an adjunct to quilting sutures for redraping the presternal skin in the entire length. Subdermal quilting sutures were avoided so as not to add additional scars for their placement. Transdermal bolster sutures reinforced the apposition of skin with the periosteum and helped us achieve similar outcomes. Pressure garment is an indispensable component of this procedure especially after the sutures and drains are removed.

\section{Conclusion}

Recreation of the medial breast footprint is the key to successful correction of congenital symmastia. Our minimally invasive approach comprising of liposuction, use of suction drains, transdermal bolster sutures and customized sternal garment is an effective method for achieving an esthetically pleasing outcome.

\section{Declaration}

All procedures performed in this case report were in accordance with the ethical standards of the institutional and national research committee and with the 1964 Helsinki.

\section{Conflict of Interest}

No conflicts of interest.

\section{References}

1 Spence RJ, Feldman JJ, Ryan JJ. Symmastia: the problem of medial confluence of the breasts. Plast Reconstr Surg 1984;73(2):261-269

2 McKissock PK. Discussion on: "symmastia: the problem of medial confluence of the breasts. Plast Reconstr Surg 1984; 73:267 
3 Salgado CJ, Mardini S. Periareolar approach for the correction of congenital symmastia. Plast Reconstr Surg 2004; 113(3):992-994

4 Piza-Katzer H, Engelhardt TO, Steiner HJ, Zelger B. Familial congenital symmastia: ultrastructurally abnormal breast tissue. Scand J Plast Reconstr Surg Hand Surg 2009;43(6):339-342

5 Sillesen NH, Hölmich LR, Siersen HE, Bonde C. Congenital symmastia revisited. J Plast Reconstr Aesthet Surg 2012;65(12): $1607-1613$
6 Sadaka MS, Allam AA. Congenital symmastia: a 3-step approach. Plast Reconstr Surg Glob Open 2016;4(12):e1158

7 Poteet SJ, Carraher A, Amjad IH, Chandawarkar R. Five-step correction of congenital Symmastia. Plast Reconstr Surg Glob Open 2015;3(3):e335

8 Karamese M, Hancı M, Abacı M, Akatekin A, Tosun Z. An easy way for congenital symmastia correction. Aesthetic Plast Surg 2014;38(2):369-372 